This item was submitted to Loughborough's Research Repository by the author.

Items in Figshare are protected by copyright, with all rights reserved, unless otherwise indicated.

\title{
Cultural probes and levels of creativity
}

PLEASE CITE THE PUBLISHED VERSION

http://dx.doi.org/10.1145/2786567.2794302

PUBLISHER

ACM

VERSION

VoR (Version of Record)

LICENCE

CC BY-NC-ND 4.0

REPOSITORY RECORD

Burrows, Alison, Val Mitchell, and C.A. Nicolle. 2019. "Cultural Probes and Levels of Creativity". figshare. https://hdl.handle.net/2134/21125. 


\section{Cultural probes and levels of creativity}

\author{
Alison Burrows \\ SPHERE IRC \\ Merchant Venturers Building \\ Woodland Road \\ Bristol BS8 1UB, UK \\ alison.burrows@bristol.ac.uk \\ Val Mitchell \\ Loughborough Design School \\ Loughborough University \\ Loughborough LE11 3TU, UK \\ v.a.mitchell@Iboro.ac.uk

\section{Colette Nicolle} \\ Loughborough Design School \\ Loughborough University \\ Loughborough LE11 3TU, UK \\ c.a.nicolle@lboro.ac.uk
}

Permission to make digital or hard copies of part or all of this work for personal or classroom use is granted without fee provided that copies are not made or distributed for profit or commercial advantage and that copies bear this notice and the full citation on the first page. Copyrights for third-party components of this work must be honored. For all other uses, contact the Owner/Author.

Copyright is held by the owner/author(s)

MobileHCI '15 Adjunct, August 24-27, 2015, Copenhagen, Denmark ACM $978-1-4503-3653-6 / 15 / 08$

http://dx.doi.org/10.1145/2786567.2794302

\begin{abstract}
Cultural probes are a design research method, which has gained prominence for being particularly suited to conducting research on sensitive topics and in personal contexts. This paper reports the methodological process of designing and deploying cultural probes to investigate the meaning of independence for older adults. We describe the rationale behind the development of individual elements of the probe kits, as well as a follow-up qualitative interview. Our discussion focuses on our experience of using this technique, with a view to informing appropriate and empowering research methodologies for older people.
\end{abstract}

\section{Author Keywords}

Older adults, inclusive design, user experience, cultural probes

\section{ACM Classification Keywords}

H.5.m. Information interfaces and presentation (e.g., $\mathrm{HCI}$ ): Miscellaneous.

\section{Introduction}

Cultural probes were originally developed in the Presence Project as a way to counter the challenges of designing new technologies for unfamiliar groups, specifically older people from diverse backgrounds [2] The authors of this method intended to encourage participants to look beyond relatively well understood needs, into the fuzzier realm of their beliefs, desires and cultural preferences. The cultural probes comprised various elements that participants could use to record their daily lives, which in turn were used in their raw 
form as inspiration for the design team. Each cultural probe package included postcards, maps, a disposable camera, photo album, and a diary.

In subsequent years, this method has taken different forms and researchers have taken different approaches to analysing the outputs of their probes. Nevertheless, probes continue to be extensively used to supplement traditional research methods to gain a rich picture of personal contexts. Examples of how cultural probes have been tailored to suit personal settings include investigating people's values in the home environment [3], understanding the design space of assistive living technologies for older people [5], and exploring user needs in a range of care settings [1].

This paper presents an adaptation of cultural probes, which were used to investigate the meaning of independence for older people in the context of coexperience.

\section{Research design}

This study was divided into two stages of data collection. The first stage used cultural probes, thus handing control of data collection to the participants and permitting insights to be obtained in an unobtrusive way. The second stage of the study was a follow-up interview with the participants, to discuss responses to the cultural probes.

Participants were purposively sampled from a previous ethnographic study, in order to include a range of characteristics of relevance to the aim of the study (e.g. people with a range of health conditions, different living circumstances, and others). The focus was on facilitating dialogue with the participants, while being mindful of the sensitive nature of certain topics.
Nine people took part in this study, four male and five female. The ages of the participants ranged from 52 to 83 years old.

Contents of the cultural probes

The cultural probes comprised four clearly labelled elements, which are described below. Participants were encouraged to do as much as they felt comfortable with and to use whatever means of expression they wanted.

(1) TELL ME POSTCARDS

The first tool consisted of two postcards, which asked participants what they associate with 'dependence' and 'independence'.

(2) SOCIAL MAP

The second tool was a map that comprised six Instrumental Activities of Daily Living (IADLs), some of which necessarily involved technology (choosing a computer, setting up a computer) and others that could be facilitated by technology (cooking, shopping, banking, booking a holiday).

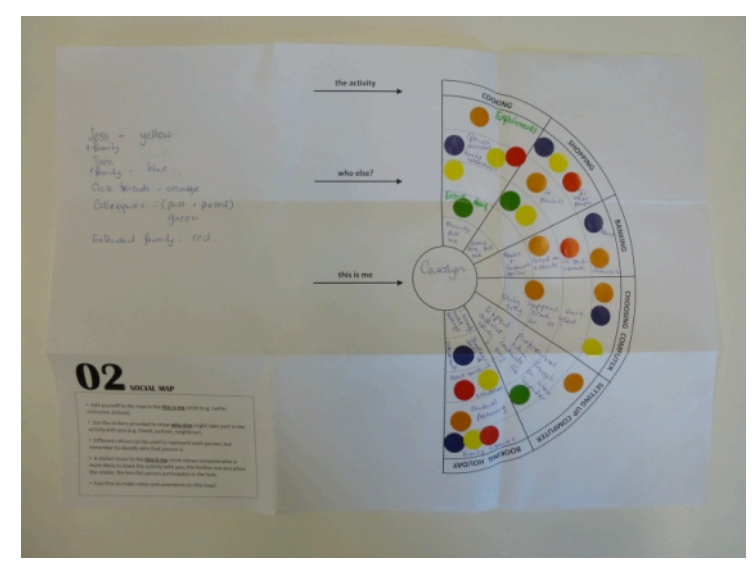

Figure 1. Example of a completed Social Map 


\section{Camera prompts}

\section{Participants were asked to} take a photo of something that:

- they like doing with other people;

- they like doing alone;

- they need help doing;

- they do with someone else even though they don't need to;

- they like to help other people do;

- they do the same way today as when they were younger:

- they do differently now from when they were younger;

- they used to do but do not anymore;

- makes them feel independent;

- makes them feel dependent.
The purpose of this tool was to identify what types of activities are likely to be shared with other people, and who these people are. This was achieved by using coloured stickers to represent the participation of different people in each activity; the further away a sticker was from the inner circle (i.e. the participant), the less that person was involved in the activity.

\section{(3) CAMERA}

Participants were given a disposable camera, with a view to gathering examples of certain types of activities (see box, left).

\section{(4) ReMEMBER WHEN SHEetS}

We were also interested in eliciting real life examples through storytelling, which is a natural way for constructing and communicating meaning. The final tool in the probe kit comprised three sheets, soliciting example stories of when the participant:

- $\quad$ asked for help even though they didn't need it;

- needed help but didn't ask for it;

- $\quad$ provided help to others.

Rationale of the cultural probes

The design of the cultural probe elements was guided by the four levels of creativity described in [4]: doing, motivated by productivity; adapting, motivated by appropriation; making, motivated by asserting an ability or skill; and creating, motivated by inspiration. The philosophy of this framework is that all people are creative and this can be expressed on different levels. For the present study, it meant that people could use different elements of our cultural probes to respond with different levels of creativity (see Table 1).

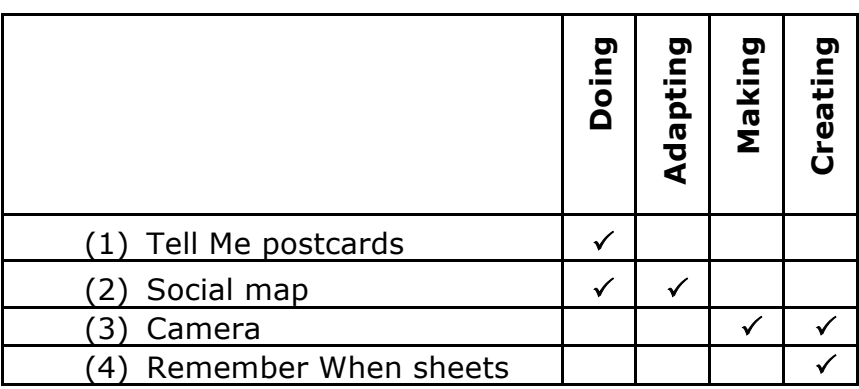

Table 1. Probe elements and levels of creativity

Follow-up interview

After all materials were provisionally analysed, we conducted a semi-structured interview with participants in their homes. This was crucial to better understanding the materials produced. The focus was to encourage participants to reflect on their responses.

\section{Lessons learned}

Be prepared for diverse responses

We had a good response rate in our cultural probe study, with all participants using every self-

documentation element. This success was probably a result of having built up a relationship with the participants during the prior ethnographic study. The outputs of the cultural probes were very different across the participants, some of whom produced concept maps (Tell Me postcards), drawings and a poem (both Remember When sheets). In addition, there were written responses and photos. For us, this diversity was an interesting and valuable outcome, which validated our rationale for designing probe elements that encouraged various forms of creativity. The follow-up interview helped us make sense of the personal meaning of these materials and therefore facilitated data analysis. 
Cultural probes can be enjoyable, as well as usersensitive

The participants reported positive experiences with using the cultural probes. They felt enabled to share their experiences and feelings appropriately. A 76-yearold male participant commented in the interview:

"I don't like tick boxes, because they don't answer the questions really."

Some participants particularly valued being given time to consider their answers. For instance, the Remember When sheets produced very personal stories about bereavement or caring for a spouse with dementia. A female participant (67 years old) used this tool to reflect on each of the stories she shared by adding an observation entitled 'Moral of this story'. For other participants, this reflection took place during the follow up interview. In the words of one male participant (52 years old):

"Hmm, you make people reflect on themselves as well. It's really good."

Giving participants control over what experiences they shared and how their shared them meant that sensitive issues surfaced freely. Participants thus shared information that they were happy to discuss with the researcher in the qualitative interview.

Sometimes technology lets you down

Participants took great care with the camera task, often taking longer to complete it because they wanted to give each example enough thought. Some participants went into their attic or garage to retrieve old objects, or arranged a collection of artefacts to tell their particular story. However, this was also the most problematic element of the cultural probes. A few participants had difficulty using the camera, as they had never used a disposable one before. Occasionally, there was confusion with how to attribute numbers to the photos so that they corresponded to the correct prompt on the list ("Is it the order in which I took the photos or the number on the camera display?"). As a result, participants wrote out a list of the elicited tasks along with a description of the corresponding photo. This was a helpful strategy for the researcher because, due to misuse of the camera (one participant) or problems developing the film, a few of the cameras produced unusable results. The researcher was able to use the list as a guide to re-take the photos alongside the participants, during the follow-up interview.

\section{References}

[1] Andy Crabtree, Terry Hemmings, Tom Rodden, Keith Cheverst, Karen Clarke, Guy Dewsbury, John Hughes, and Mark Rouncefield. 2003. Designing with care: Adapting cultural probes to inform design in sensitive settings. In Proc. OZCHI 2003, 4-13.

[2] Bill Gaver, Tony Dunne, and Elena Pacenti. 1999. Design: Cultural Probes. Interactions, 6 (Jan./Feb. 1999), 21-29.

[3] Victoria Haines, Val Mitchell, Catherine Cooper, and Martin Maguire. 2007. Probing user values in the home environment within a technology driven Smart Home project. Personal and Ubiquitous Computing 11 (June 2007), 349-359.

[4] Elizabeth B-N Sanders and Pieter Jan Stappers. 2008. Co-creation and the new landscape of design. CoDesign 4, 1 (June 2008), 5-18.

[5] Joseph Wherton, Paul Sugarhood, Rob Procter, Mark Rouncefield, Guy Dewsbury, Sue Hinder, and Trisha Greenhalgh. 2012 Designing assisted living technologies 'in the wild': Preliminary experiences with cultural probe methodology. BMC 12, 1 (Dec. 2012): 18 